\title{
Panorama dos rompimentos de barragens de rejeitos de minério no mundo
}

\author{
World overview of the tailings dam failures
}

Matheus de Oliveira Reis Graduando em Geografia pela UFMG, Brasil matheusor95@hotmail.com

Ana Carolina Mayrinck Braga de Moura Graduanda em Geografia pela UFMG, Brasil anamayrinck@hotmail.com

\author{
Guilherme Eduardo Macedo Cota \\ Doutorando em Geografia e Análise Ambiental pela UFMG, Brasil \\ guilhermebhmg@hotmail.com \\ Antônio Pereira Magalhães Junior \\ Professor Titular do Departamento de Geografia da UFMG, Brasil \\ antonio.magalhaes.ufmg@gmail.com
}

\begin{abstract}
Resumo
A mineração é um dos mais importantes setores da economia mundial, exercendo grande impacto na evolução tecnológica da humanidade. O século XX foi um período decisivo para o setor, no qual a exploração mineral cresceu de forma substancial em termos internacionais. Paralelamente, houve um aumento do número de casos de rompimentos de barragens de rejeitos de minério no mundo, inclusive no Brasil. Nesse sentido, o trabalho apresenta um panorama sobre eventos de rompimentos de barragens de rejeitos entre os anos de 1910 e 2019. Os dados obtidos apontam para uma predominância de casos de rompimento ao longo das décadas de 1960, 1970 e 1980, além de uma transição da concentração dos eventos da Europa para a América do Sul e para a Ásia. É dada ênfase a quatro importantes desastres: Aznalcóllar (Espanha, 1998), Mount Polley (Canadá, 2014), Fundão (Brasil, 2015) e Brumadinho (Brasil, 2019). O texto traz características da legislação minerária nesses países, associando com os eventos citados.
\end{abstract}

Palavras-chave: Desastres ambientais; Mineração, Rompimento de barragens de rejeitos.

\begin{abstract}
Mining is one of the most critical sectors of the world economy and has a significant impact on the technological evolution of humanity. The 20th century was a crucial period for the sector when mineral exploration grew substantially in universal terms. At the same time, there has been an increase in the number of tailings dam failures cases in the world, including Brazil. There was a predominance of failures throughout the 1960s, 1970s, and 1980s in addition to a transition of the events concentration from Europe to South America and Asia. In this sense, the paper presents an overview of tailings dam failures events between 1910 and 2019, detailing four major disasters: Aznalcóllar (Spain, 1998), Mount Polley (Canada, 2014), Fundão (Brazil, 2015) and Brumadinho (Brazil, 2019). Characteristics of mining legislation are presented in each country.
\end{abstract}

Keywords: Environmental disasters; Mining, Tailing dam failures. 


\section{INTRODUÇÃO}

Desde os primórdios da humanidade, particularmente a partir da Idade dos Metais, o homem utiliza técnicas de exploração mineral para diversos fins. Inicialmente, o foco era a fabricação de ferramentas para as atividades de subsistência, como a caça e a pesca. Contudo, com o passar do tempo, a exploração foi sendo designada para outras finalidades. No mundo contemporâneo os minerais passaram a ser empregados em uma variada gama de atividades, como a produção de ligas metálicas para utilização na indústria automobilística e naval e a aplicação na indústria bioquímica e de eletroeletrônicos. Tal diversificação evidencia a importância da atividade minerária e dos recortes espaciais onde ocorre para a economia global. No Brasil, a mineração responde por $1,4 \%$ do Produto Interno do País (PIB), tendo papel de destaque nas discussões políticas e econômicas (IBRAM, 2018).

Em termos internacionais, a mineração passou por diversos ciclos ao longo da história, apresentando particularidades em termos de minerais explorados e/ou de técnicas utilizadas. No Brasil, o Ciclo do Ouro, por exemplo, se desenvolveu com base no garimpo de depósitos sedimentares fluviais ao longo do século XVII. Atualmente, o modelo de exploração mineral pode empregar diferentes técnicas em função, dentre outros, do nível tecnológico da atividade e do volume de material extraído, como os barramentos para o armazenamento dos rejeitos gerados pelos processos de extração e beneficiamento mineral.

Em muitos países, os avanços tecnológicos nas práticas exploratórias e o desenvolvimento de políticas públicas voltadas à garantia de qualidade ambiental e à recuperação de áreas degradadas vem incrementando o controle dos danos ambientais da exploração mineral ao longo dos anos (GUDYNAS, 2012). Não obstante, o grande volume de material explorado somado à negligência dos aparatos de gestão, particularmente órgãos licenciadores e fiscalizadores e as próprias mineradoras no controle de seus empreendimentos, ainda geram significativos passivos ambientais para a sociedade.

Nas últimas décadas, os impactos da atividade minerária em nível mundial têm suscitado novos questionamentos em âmbitos político e acadêmico, fato intensificado por recentes eventos envolvendo o rompimento de barragens de rejeitos de minério em diversos países, como o Brasil. Dentre esses casos destacam-se, em termos dos impactos gerados, o rompimento das barragens de Aznalcóllar, em 1998 na Espanha; de Mount Polley, em 2014 no Canadá; de Fundão, em 2015, e de Brumadinho, em 2019, no Brasil.

Destarte, o presente trabalho visa elaborar um panorama dos eventos de rompimento de barragens de rejeitos de minério em âmbito internacional, destacando o histórico dos casos relatados e aspectos como tipo de exploração, causa dos rompimentos e recortes espaciais de ocorrência. 
Ademais, busca-se apontar reflexões acerca dos fatores condicionantes dos rompimentos, bem como as medidas político-administrativas adotadas para evitar novos desastres. Espera-se que o panorama elaborado possa contribuir para os avanços nas discussões e nos conhecimentos sobre o tema.

\section{PROCEDIMENTOS METODOLÓGICOS}

O trabalho foi realizado por meio de uma detalhada pesquisa bibliográfica acerca dos rompimentos de barragens de rejeitos de minério no mundo. Foram analisados trabalhos científicos e repositórios digitais de diferentes organizações que relataram a ocorrência de rompimentos com estudos verticalizados e/ou que fizessem a compilação histórica dos eventos relatados. Nesse sentido, vale destacar que os estudos que quantificam o número de barragens apresentam, muitas vezes, dados conflitantes e com valores distintos. Tal aspecto decorre da metodologia aplicada em cada estudo, bem como as bases de dados que, por sua vez, dependem da disponibilidade de informações fornecidas em cada país e/ou região.

A organização internacional não governamental International Commission on Large Dams (ICOLD) fornece um fórum para a troca de conhecimento e experiência em engenharia de barragens, contemplando os mais variados tipos de estruturas. Contudo, o ICOLD possui um catálogo de 59.071 barragens de categoria "grande" no mundo que, segundo seus critérios, corresponde a estruturas de 15 metros ou mais de altura, ou então entre 5 e 15 metros, mas que retêm um volume superior a três milhões de metros cúbicos de água (ICOLD, 2019b). Dentre as principais finalidades dos barramentos levantados pelo ICOLD, não se destacam estruturas de contenção de rejeito de minério, foco deste trabalho, e sim estruturas destinadas ao armazenamento de água para fins de controle de vazões, geração de energia hidroelétrica, irrigação e outros usos.

Não obstante, para se destacar a dificuldade de realização deste levantamento e da discrepância das informações de acordo com a fonte analisada, o corpo de engenheiros do exército dos Estados Unidos tem produzido um banco de dados a respeito das barragens existentes no país chamado National Inventory of Dams (NID). Somente nos Estados Unidos há mais de 90.000 barragens de distintas categorias (NID, 2019). Por conseguinte, a estimativa exata do número de barragens no mundo, considerando tipos e tamanhos diferentes, permanece uma incógnita.

A pesquisa bibliográfica focou em estudos que se concentram em barragens de rejeitos de minério. Um dos trabalhos de referência é o de Azam e Li (2010) que fornece dados sobre barragens entre as décadas de 1910 e 2000, obtidos a partir de uma ampla base de dados disponibilizados pelo ICOLD, World Information Service on Energy (WISE), United Nations Environmental Protection (UNEP), United States Commission On Large Dams (USCOLD) e 
United States Environmental Protection Agency (USEPA). No caso dos eventos de rompimentos de barragens de rejeitos ocorridos a partir da década de 2010, privilegiou-se a consulta dos dados disponibilizados digitalmente pela World Information Service on Energy (WISE), por meio do WISE Uranium Project (WISE URANIUM PROJECT, 2019). Apesar destas fontes fornecerem uma compilação do histórico de rompimento de barragens de rejeitos no mundo, não são documentadas todas as suas causas, apesar da sinalização de possíveis fatores que desencadearam o colapso das estruturas. Isso se deve à ausência de informações por parte dos órgãos responsáveis pela apuração dos eventos.

Para fornecer um panorama das discussões acerca das mudanças na legislação no tocante à segurança de barragens de rejeitos de minério após os eventos de rompimento, foi dada ênfase aos casos de Aznalcóllar na Espanha, Mount Polley no Canadá, Fundão e Brumadinho no Brasil. A escolha se deve à sua ampla divulgação pela mídia e às suas implicações nas discussões levantadas em âmbito político e acadêmico sobre a segurança de barragens que, por sua vez, levaram a alterações nas normas legais vigentes.

Neste sentido, o trabalho traz, a partir das alterações legais e normativas sobre barragens de rejeitos de minério, um panorama das discussões tangentes aos barramentos após os rompimentos, evidenciando similaridades, tendências e diferenças nas medidas legais adotadas.

\section{PANORAMA MUNDIAL DOS ROMPIMENTOS DE BARRAGENS DE REJEITOS}

Um arcabouço legal restritivo associado a um aparato de gestão eficiente favorece o maior controle dos barramentos de minério. Contudo, não raro as realidades nacionais mostram sistemas gestores pouco eficientes e sem a preocupação de catalogação, monitoramento e fiscalização das barragens existentes (TAKAR, 2019). Consoante, o panorama internacional do número de eventos de rompimentos de barragens também permanece incerto.

O ICOLD (2019a) tem registrado cerca de 300 desastres com grandes represas com diversas finalidades ao longo da história, enquanto Zhang et al. (2007) citam mais de 900 casos registrados na literatura, excluindo a China, sendo que a maioria está relacionada a barragens de terra. Em relação às barragens de rejeitos de minério, a United Nations Environment Programme (UNEP) estima que há cerca de 3.500 barramentos no globo (UNEP, 2017).

$\mathrm{O}$ número de barragens de rejeitos começou a crescer de maneira significativa após a Segunda Guerra Mundial, quando a demanda por metais e minerais aumentou fortemente devido às necessidades de reconstrução das nações afetadas (AZAM; LI, 2010). Consequentemente, também cresceram os casos de rompimentos. 
Foram identificados, na literatura, 250 eventos de rompimento de barragens de rejeitos de minério entre os anos de 1910 e $2019^{1}$. Desses, grande parte ocorreu entre os anos de 1960 e 1980 (Figura 1), principalmente na América do Norte e na Europa (Figura 2).

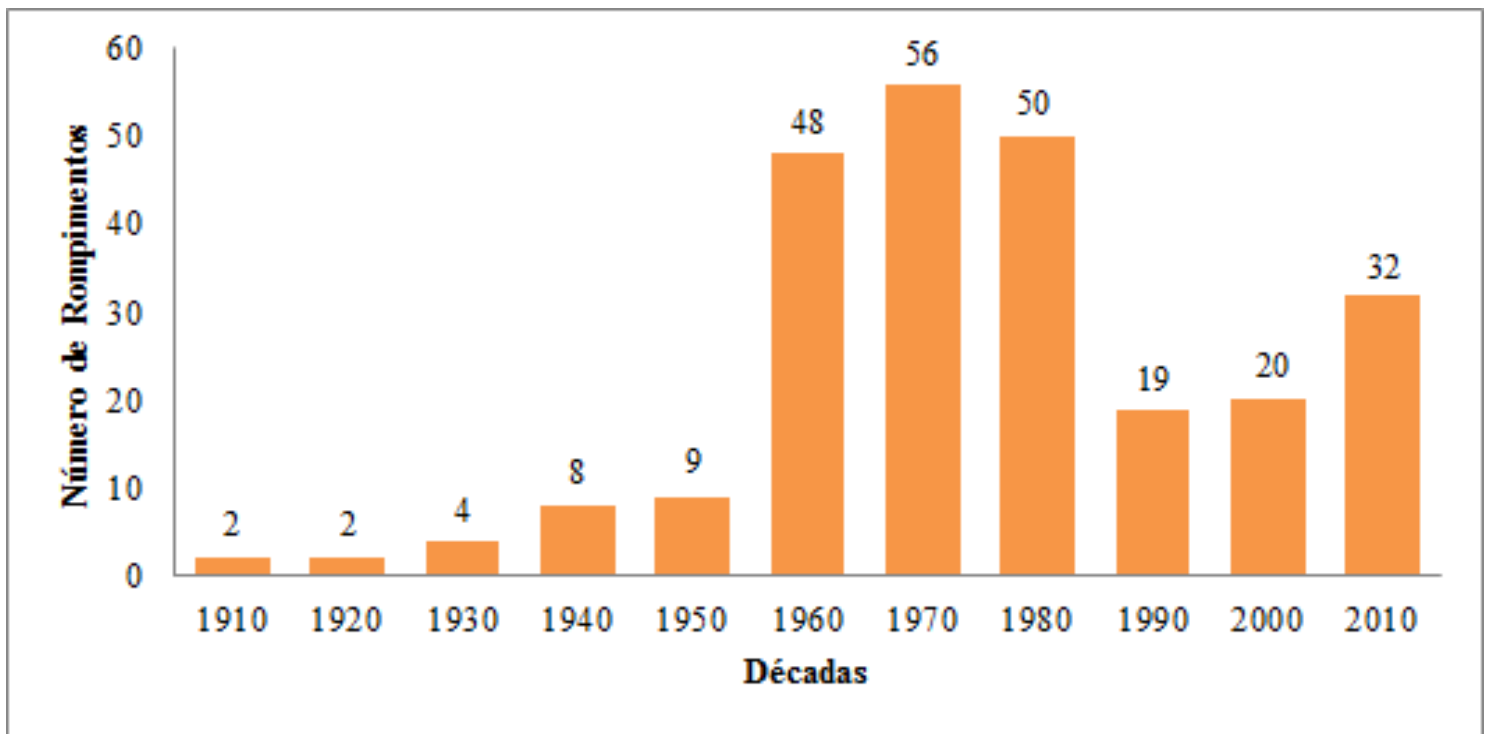

Figura 1 - Número de rompimentos de barragens de rejeitos por década - Dados entre 1910 e 2019. Fontes: Azam e Li (2010) e WISE Uranium Project (2019).

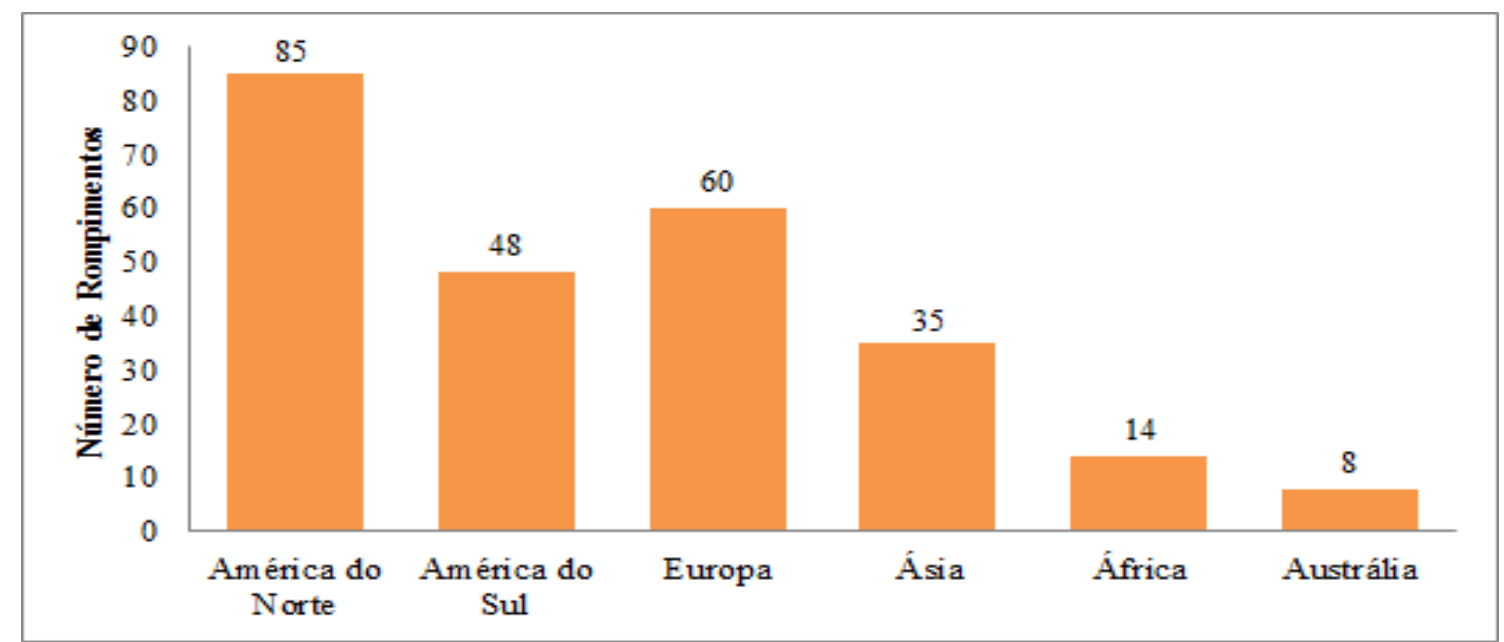

Figura 2 - Número de rompimentos de barragens de rejeitos por continente entre 1910 e $2019^{2}$.

Fontes: Azam e Li (2010) e WISE Uranium Project (2019).

Com o avanço das técnicas de construção civil e da rigidez dos critérios de segurança em vários países, o número de rompimentos começou a cair a partir da década de 1990. Apesar de uma elevação na década de 2010, os números de casos não alcançam os dos anos 1960, 1970 e 1980. Não obstante, há a possibilidade de inúmeros casos não terem sido reportados (D’AGOSTINO, 2008).

\footnotetext{
${ }^{1}$ Os dados acessados correspondem a eventos ocorridos até o dia 19/07/2019.

2 Como não foram encontrados dados relativos a rompimentos de barragens em outros países da Oceania além da Austrália, optou-se por individualizar este país no gráfico de continentes.
} 
Com base na distribuição espaço-temporal dos eventos, é possível afirmar que houve certa migração da concentração dos casos de rompimento da Europa para a América do Sul e, sobretudo, para a Ásia a partir do século XXI. Enquanto ao longo do século XX foram registrados 52 casos na Europa e apenas 17 na Ásia, somente a partir de 2010 já foram registrados 12 casos na Ásia, mas apenas dois na Europa (AZAM; LI, 2010; WISE URANIUM PROJECT, 2019).

$\mathrm{O}$ crescente número de casos na Ásia parece ter relação direta com a expansão da economia chinesa e sua crescente demanda por metais (AZAM; LI, 2010). A partir de 2010 já foram registrados três casos no país, mas, não obstante, Mianmar apresenta quatro casos nesse período, todos envolvendo barramentos de rejeito de exploração de jade. Os dois países respondem por 58,33\% dos casos relatados na Ásia (WISE URANIUM PROJECT, 2019).

A América do Norte esteve na vanguarda de casos de rompimento de barragens de rejeitos de minério ao longo do século XX, mas esse cenário se alterou na virada para o século XXI. A partir de 2010 foram registrados oito casos, mesmo número da América do Sul, com destaque para o Canadá com quatro ocorrências. Na América do Sul foram relatados casos somente no Brasil (cinco ocorrências - 62,5\% do total no continente) e no Peru (três ocorrências - 37,5\% do total) ao longo da década (WISE URANIUM PROJECT, 2019).

Geralmente, as causas dos rompimentos não estão claras na literatura. Quando apontados, os fatores causadores devem ser entendidos como uma sinalização dos aspectos desencadeadores dos eventos. Comumente, há uma ausência de informações para se determinar, de maneira inequívoca, os fatores causais, além de vários desastres ainda serem investigados.

A análise das causas de rompimentos de barragens seguiu as categorias estabelecidas por Azam e Li (2010), inclusive as relativas a eventos pós-2010 e relatadas pelo WISE Uranium Project (2019). A sua categorização é uma tarefa complexa, pois a sua referência na literatura pode ocorrer a partir de critérios e metodologias distintas que, muitas vezes, apontam o mesmo mecanismo causador do desastre, mas de maneiras diferentes. Ademais, em muitos casos, não há um único mecanismo causador, havendo um conjunto de fatores associados que levaram ao rompimento. Como exemplo, dependendo do tipo de análise adotada, a causa "infiltração" pode ser associada a "falhas no gerenciamento de barragens". Assim, conforme destacado, as causas apontadas na Figura 3 devem ser entendidas como sinalizações acerca dos fatores que levaram ao rompimento. 


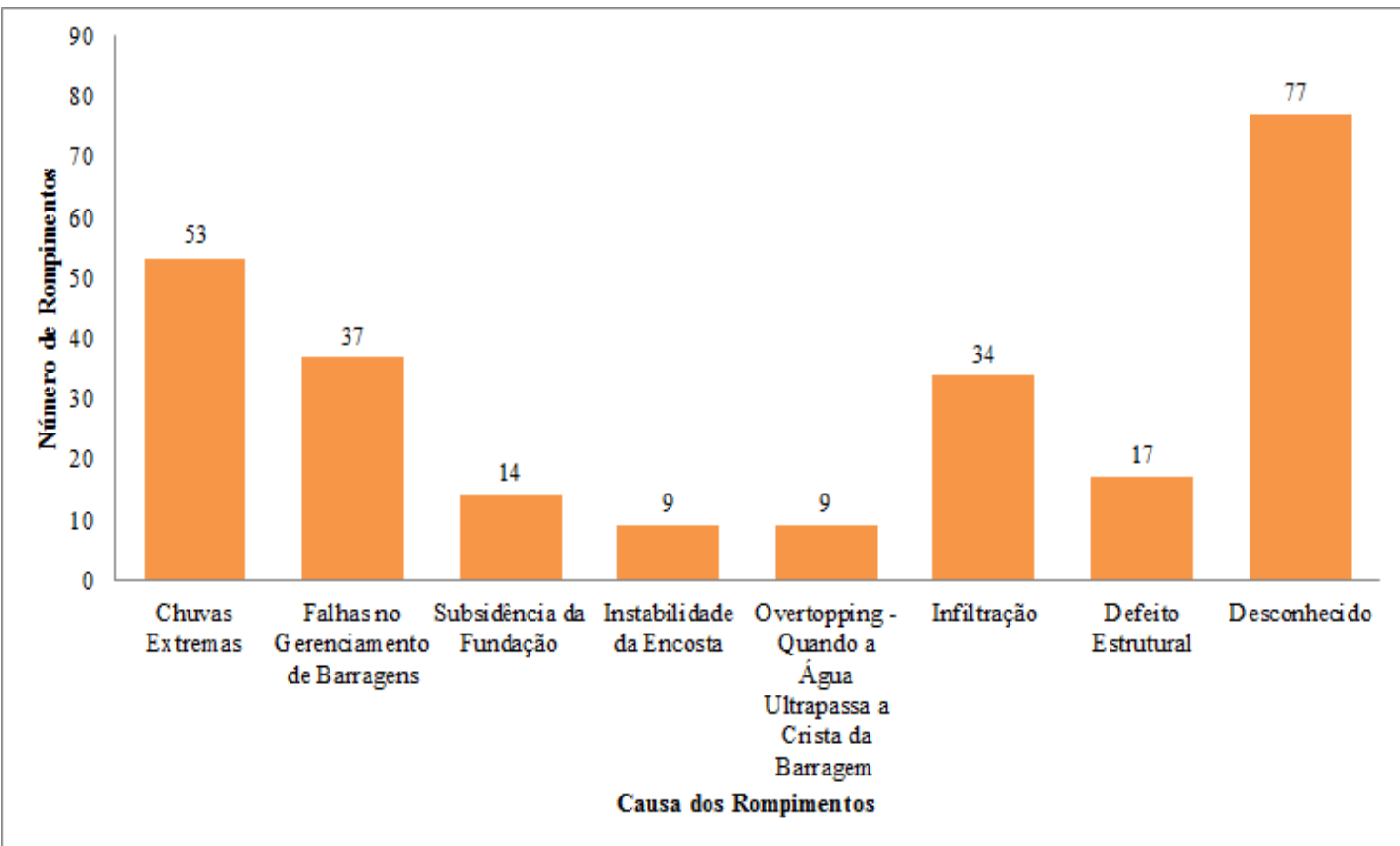

Figura 3 - Principais causas do rompimento de barragens de rejeitos entre 1910 e 2019.

Fontes: Azam e Li (2010) e WISE Uranium Project (2019).

Dentre os 250 rompimentos ocorridos nos últimos 119 anos, 30,8\% (77 casos) não tiveram causas determinadas e em 20,4\% (51 eventos, sendo todos ocorridos antes do ano 2000) não há informações sobre as causas na literatura (AZAM; LI, 2010). Em um conjunto de 49,6\% dos casos, as principais causas foram associadas a condições de chuvas extremas, falhas no gerenciamento de barragens e infiltrações. Outras causas incluem subsidência da fundação, instabilidade da encosta, overtopping, defeito estrutural.

Da mesma forma que o número exato de rompimentos de barragens de rejeitos é incerto, muitos dos eventos reportados carecem de informações básicas, o que dificulta o fomento a aparatos legais de segurança nas áreas afetadas. Apesar dos acidentes envolverem rejeitos minerais variados, destacam-se as barragens de mineração de cobre, ouro e carvão (WISE URANIUM PROJECT, 2019).

A seguir são descritos quatro casos de rompimentos de barragens de rejeitos de minério que ganharam grande destaque midiático e acadêmico pelas circunstâncias em que ocorreram, pelos danos gerados e pelas discussões sobre segurança de barragens que suscitaram (que serão melhor apresentadas no capítulo 4).

\subsection{A Barragem de Aznalcóllar}

No dia 25 de abril de 1998, uma barragem de contenção de rejeito de mineração de zinco da mina de Los Frailes, pertencente à mineradora Boliden, na cidade espanhola de Aznalcóllar, rompeu liberando mais de cinco milhões de metros cúbicos de rejeito contendo água com ácidos e 
altos níveis de zinco e cádmio (MEHARG et al., 1999). Rapidamente, o rio Agrio foi afetado pela lama de rejeito, e posteriormente o importante rio Guadiamar (Figura 4). O Guadiamar atravessa a região da Andaluzia e deságua no Parque Nacional de Doñana, considerado patrimônio mundial da humanidade pela Organização das Nações Unidas para a Educação, a Ciência e a Cultura (UNESCO). O Parque compreende a maior reserva biológica da Europa, englobando unidades ambientais mediterrâneas particulares, como as Marismas do Guadalquivir (MAGALHÃES JÚNIOR, 2017). Apesar dos esforços para conter o avanço dos rejeitos, cerca de $40 \mathrm{~km}$ do rio foram atingidos, impactando a biota aquática e diversas espécies de aves.

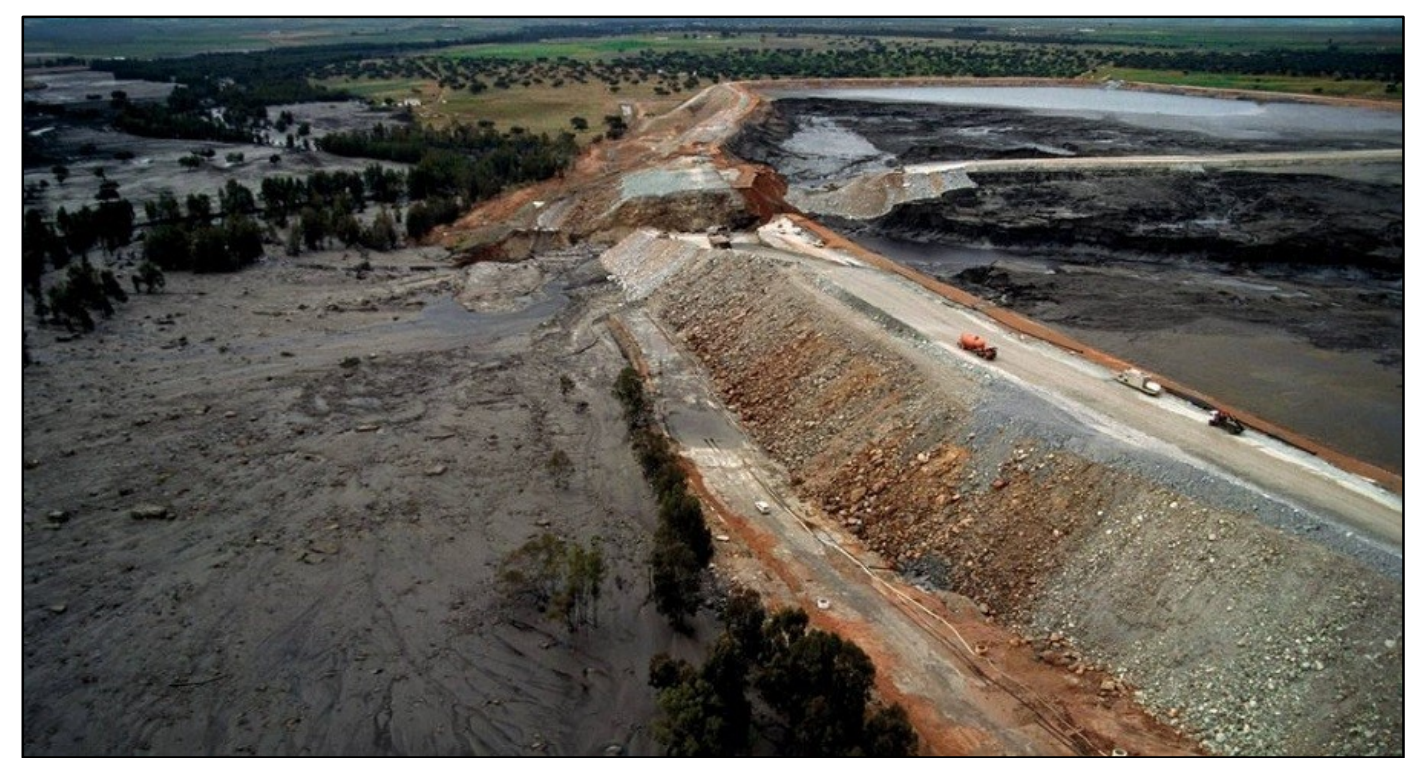

Figura 4 - Barragem de Aznalcóllar (Espanha) e trecho do rompimento. Fonte: Ecologistas En Acción ${ }^{3}$.

Estudos apontaram falhas nos aspectos geotécnicos da estrutura que levaram à ruptura de uma das paredes da barragem, como diferenças no volume de material armazenado em diferentes áreas do barramento. Também foi detectado o importante papel da água nos poros do material armazenado, favorecendo a liquefação, além de outros fatores (ALONSO; GENS, 2006; GENS; ALONSO, 2006).

\subsection{A Barragem de Mount Polley}

Localizada na Província da Colúmbia Britânica, região das montanhas Cariboo, no Canadá, a mina de Mount Polley é operada pela Mount Polley Mining Corporation, subsidiária da Imperial Metals, extraindo ouro e cobre a céu aberto e, também operações subterrâneas (MARSHALL, 2017). A barragem se localiza entre o Lago Bootjack e o Lago Polley, ficando a cerca de $100 \mathrm{~km}$

\footnotetext{
3 Disponível em: <http://www.mining.com/spanish-activists-reject-reopening-los-frailes-mine/>. Acesso em: 22 de julho de 2019.
} 
por estrada de Williams Lake, uma importante cidade regional a sudoeste da mina. As operações foram iniciadas em 1997 e paralisadas entre setembro de 2001 e março de 2005, devido à queda no preço dos metais, sendo retomadas ininterruptamente até agosto de 2014 (BROWN et al., 2016).

No dia 4 de agosto de 2014, a barragem rompeu liberando mais de 24 milhões de metros cúbicos de água e rejeitos (MARSHALL, 2017). A força do material liberado destruiu uma grande área florestal e fluiu ao longo do Córrego Hazeltine, chegando ao Lago Polley, o que elevou o seu nível em cerca de um metro e meio (WILLIAMS, 2014). O material prosseguiu fluindo ao longo do Córrego e atingiu o Lago Quesnel, formando um delta de rejeitos na sua margem (ADEN, 2018), conforme mostra a Figura 5.

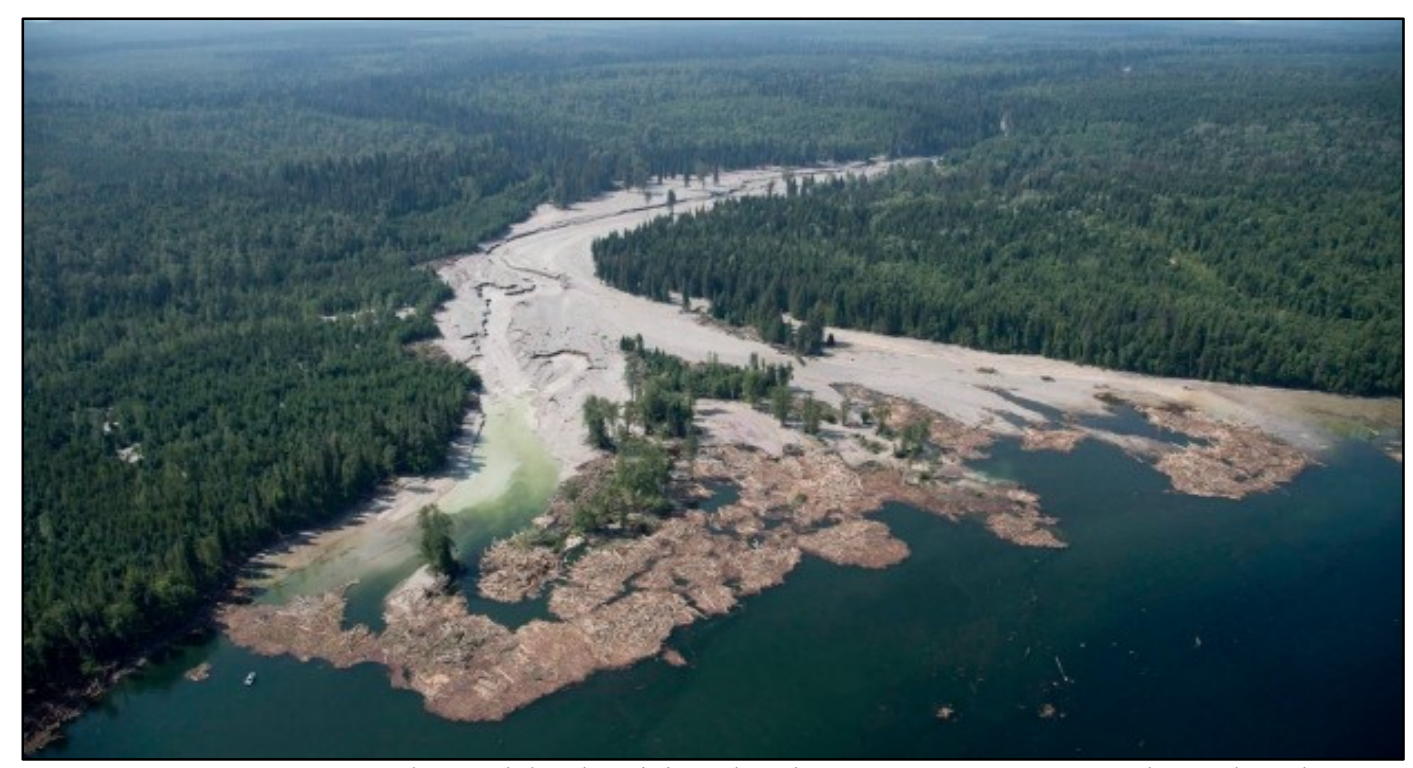

Figura 5 - Formação de um delta de rejeitos de mineração no Lago Quesnel gerado pelo rompimento da barragem de Mount Polley - Canadá.

Fonte: Jonathan Hayward/The Canadian Press ${ }^{4}$.

Vários estudos apontaram para uma falha no design da barragem como o motivo do rompimento. Arafat (2017) destaca que o projeto não levou em conta a complexidade do ambiente periglacial local. Os projetistas não identificaram uma camada contínua lacustre-glacial procedente de um antigo lago glacial que continha principalmente argilas. Com o processo constante de alteamento da barragem e o aumento do peso com o acréscimo de água e rejeitos, a camada de gelo e argila se quebrou e deslizou, rompendo o barramento.

O acidente não ocasionou nenhuma morte, mas a contaminação do Lago Quesnel por metais pesados, como cobre (THE CANADIAN PRESS, 2015), gerou grande preocupação, já que faz parte da bacia hidrográfica do rio Fraser, o principal da Província. O Lago é um manancial de abastecimento de água e berço de reprodução de salmões vermelhos. Como a pesca é uma das

4 Disponível em: <https://www.ctvnews.ca/politics/future-of-quesnel-lake-still-unclear-after-mount-polley-minedisaster-report-1.2360009>. Acesso em: 22 de julho de 2019. 
principais atividades econômicas da região, várias cidades e comunidades foram prejudicadas e sofrem impactos do desastre até hoje.

\subsection{As Barragens de Fundão e do Córrego do Feijão}

O rompimento da barragem de Fundão, em 2015, e da barragem da mina do Córrego do Feijão, em 2019, ocorreram na província mineral do Quadrilátero Ferrífero, em Minas Gerais, uma das principais regiões produtoras de minério de ferro do país. Ambos os casos são bastante representativos, considerando o curto espaço de tempo em que ocorreram e os múltiplos danos ambientais, sociais e econômicos gerados.

Em 5 novembro de 2015, a barragem de Fundão, localizada no município de Mariana e pertencente à mineradora Samarco S.A. (joint-venture das mineradoras Vale S.A. e da BHP Billiton) rompeu, lançando cerca de 60 bilhões de litros de rejeito de minério de ferro liquefeito nos sistemas fluviais subjacentes à barragem (MILANEZ; LOSEKANN, 2016). O grande volume de material liberado percorreu mais de $600 \mathrm{~km}$ das cabeceiras da bacia do rio Doce até a sua foz no oceano Atlântico, sendo considerado um dos maiores desastres ambientais ocorridos no Brasil.

Dois distritos de Mariana, Bento Rodrigues e Paracatu de Baixo, foram destruídos, ao menos parcialmente, pela lama de rejeitos (Figura 6), ocasionando 19 mortes e um desaparecimento (MENDES e OLIVEIRA, 2019). O rompimento também deixou diversas cidades em Minas Gerais e Espírito Santo sem abastecimento de água potável durante semanas, além de milhares de hectares de áreas de plantio e de uso para outras atividades produtivas impactados (MILANEZ; LOSEKANN, 2016).

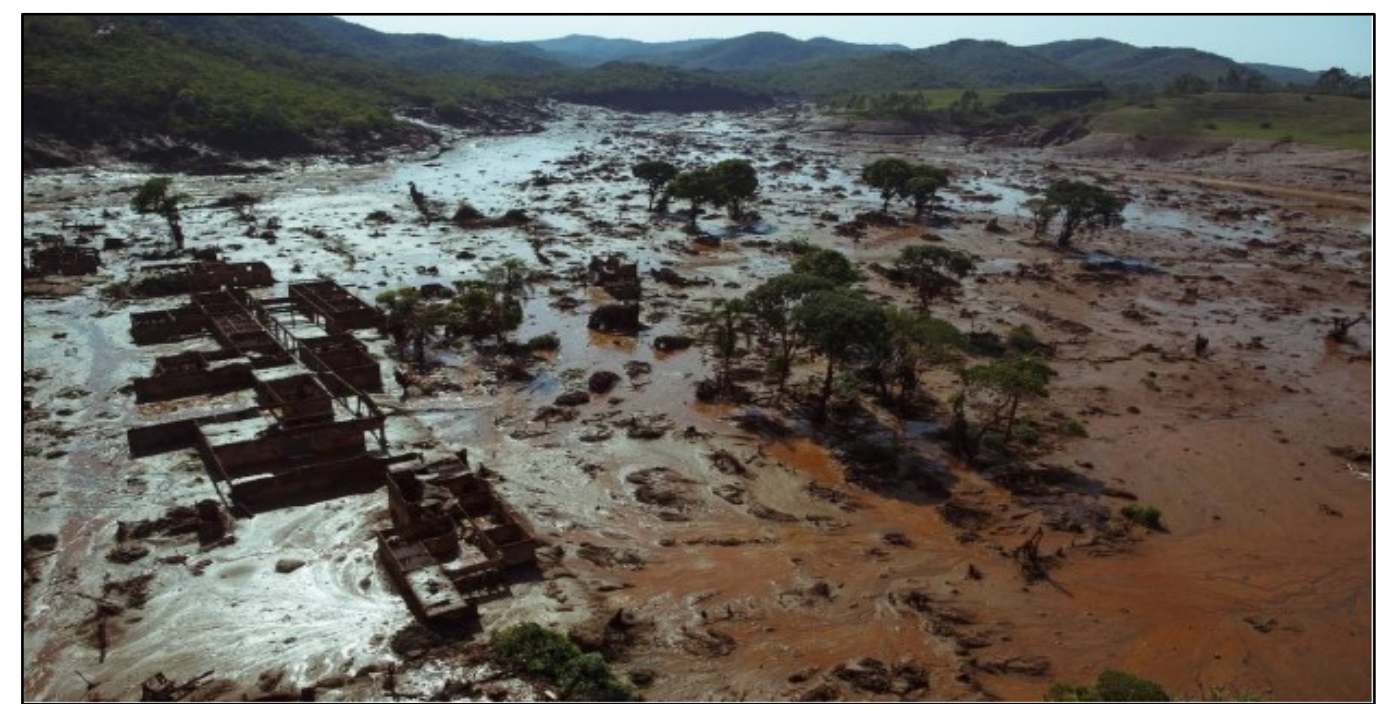

Figura 6 - Distrito de Bento Rodrigues após o rompimento da barragem de Fundão. Fonte: Daniel Marenco - 06/11/2015 / Arquivo O Globo ${ }^{5}$.

\footnotetext{
${ }^{5}$ Disponível em: <https://oglobo.globo.com/brasil/acidente-em-mariana-o-maior-da-historia-com-barragens-de-rejeitos18067899>. Acesso em: 22 de julho de 2019.
} 
Cerca de três anos após o rompimento da barragem de Fundão, no dia 25 de janeiro de 2019, a barragem B1 da mina do Córrego do Feijão, também voltada para a exploração de ferro e pertencente à mineradora Vale S.A., rompeu no município de Brumadinho. Estima-se que cerca de 12 milhões de metros cúbicos de rejeito tenham sido despejados na bacia do rio Paraopeba (MENDES e OLIVEIRA, 2019) (Figura 7).

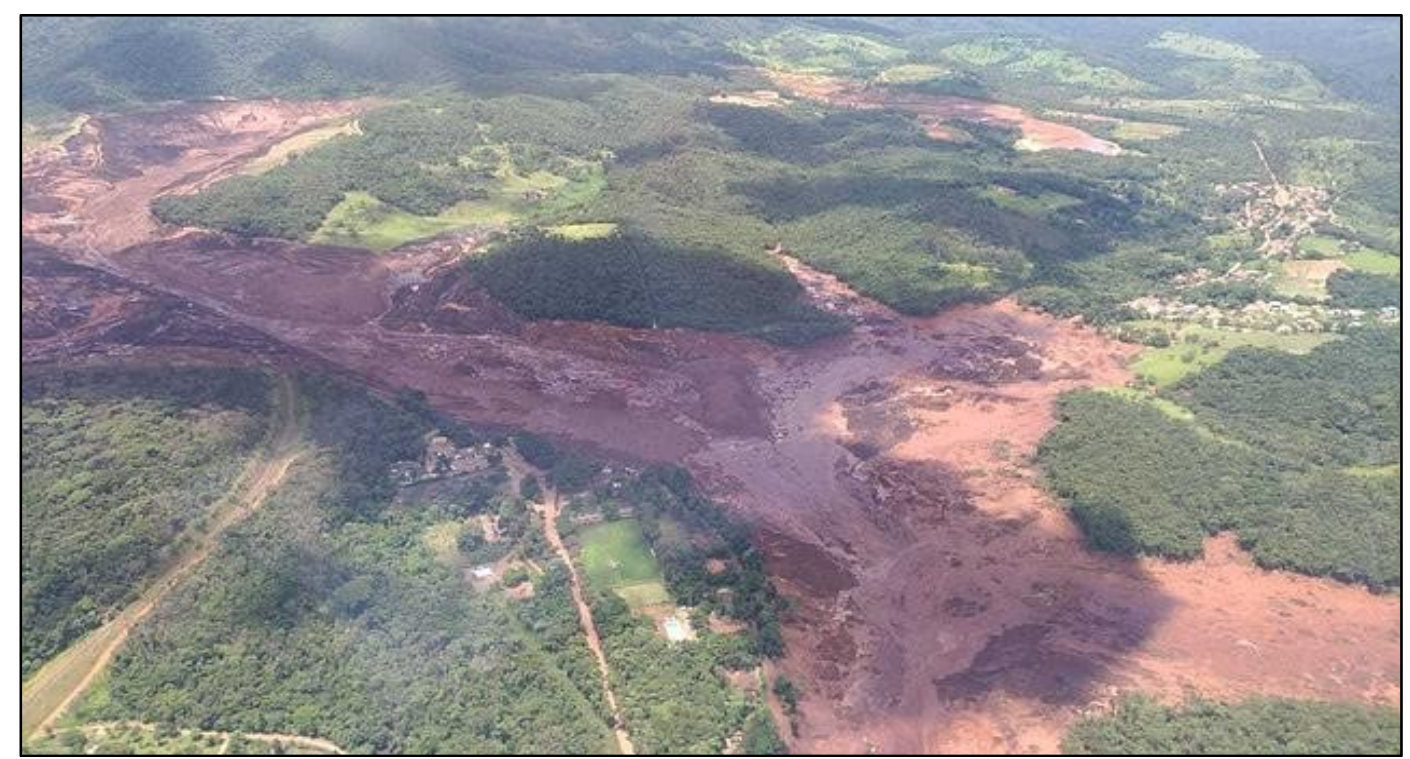

Figura 7 - Imagem da área afetada pelo rompimento da barragem B1 em Brumadinho.

Fonte: Divulgação/Corpo de Bombeiros de Minas Gerais ${ }^{6}$.

Após o rompimento da barragem, a lama atingiu uma estrutura onde estavam presentes empregados e prestadores de serviço da Vale S.A., bem como diversas propriedades rurais, ocasionando 247 mortes e 23 desaparecidos $^{7}$ (EXAME, 2019). Este rompimento se configura como o maior acidente de trabalho ocorrido no Brasil (SOUZA; FELLET, 2019) e possivelmente está entre os quatro primeiros casos de rompimentos de barragens de rejeitos com mais vítimas no mundo (WISE URANIUM PROJECT, 2019).

Vale destacar que três dos cinco eventos envolvendo rompimentos de barragens de rejeitos ocorridos a partir de 2010, no Brasil, englobam barramentos para contenção de rejeito de minério de ferro, todos na província mineral do Quadrilátero Ferrífero.

\section{ROMPIMENTOS DE BARRAGENS E EVOLUÇÃO DA LEGISLAÇÃO}

A Política Nacional de Segurança de Barragens (PNSB) define parâmetros legais para regulamentar as barragens de rejeitos de mineração no Brasil (BRASIL, 2010). É ela que exige do empreendedor o Plano de Segurança de Barragem (PSB), um dos instrumentos previstos para a

\footnotetext{
6 Disponível em: <https://cbn.globoradio.globo.com/media/audio/241531/barragem-se-rompe-e-lama-se-espalha-porbrumadinho.htm>. Acesso em: 22 de julho de 2019.

${ }^{7}$ Número de vítimas atualizado até 04 de julho de 2019 (EXAME, 2019).
} 
operação de uma barragem de rejeitos. A fiscalização das barragens é feita pela Agência Nacional de Mineração (ANM) e, particularmente em Minas Gerais, também pelos órgãos e entidades vinculados ao Sistema Estadual de Meio Ambiente e Recursos Hídricos (SISEMA). Contudo, o quadro de recursos humanos para realizar a fiscalização é reduzido, contando atualmente com apenas oito profissionais dedicados exclusivamente à gestão da segurança de barragens no Brasil. Este cenário limita o poder de ação desses órgãos e dificulta a supervisão dos 769 barramentos de rejeito cadastrados no país. Assim, percebe-se um descompasso entre a legislação e a gestão dos barramentos, tendo em vista que, em média, um profissional é responsável por fiscalizar cerca de 96 barragens.

Ademais, nota-se certa permissividade dos órgãos fiscalizadores quanto à mineração, pois há o estabelecimento de uma série de normas para a construção e manutenção de barragens, mas na prática há pouca exigência em se cumprir os instrumentos estabelecidos na PNSB (COTA et al., 2019). O que se percebe é um descompasso entre o que diz a legislação e a prática da gestão dos barramentos, principalmente considerando-se que não há garantias que um representante do SISEMA ou da ANM acompanhe todo o processo de licenciamento, bem como a efetiva implantação e manutenção das obras. Logo, não há garantia de que todas as diretrizes da Lei $n^{\circ}$ 12.334, de 20 de setembro 2010 sejam cumpridas (BRASIL, 2010).

Dessa forma, a ineficácia dos processos de fiscalização e as limitações da legislação vigente contribuem para que as mineradoras atuem deliberadamente de acordo com os seus interesses. É de se esperar que surjam relações muito próximas entre o setor minerário e os governos nas diferentes esferas territoriais. Um exemplo ilustrativo é a prática do lobby, caracterizado por processos de pressão sobre algum poder da esfera política visando influenciar na tomada de decisões em prol de alguma causa ou apoio (CAMPOS, 2017).

Em países como os Estados Unidos, por exemplo, o lobby é uma atividade regulamentada, mas no Brasil a ausência de um aparato normatizador abre portas para abusos na defesa dos interesses setoriais. Até 2015, quando foi aprovada a Lei $\mathrm{n}^{\mathrm{o}} 13.165^{8}$, de 29 de setembro de 2015, era permitida uma prática comum de lobby no país via doação de recursos financeiros por parte de empresas para campanhas eleitorais. Por sua vez, a Columbia Britânica, onde ocorreu o desastre de Mount Polley, é uma das poucas províncias canadenses que permitem que empresas façam doações sem restrições para a classe política (MARSHALL, 2017). Mesmo que o lobby possa parecer ser uma atividade suspeita, não se configura como uma prática ilícita (JUSBRASIL, 2015), mas a falta de transparência e regulamentação pode encobrir a ausência de limites na defesa dos próprios interesses e resultar em crimes como suborno e, consequentemente, corrupção. A execução destes

\footnotetext{
${ }^{8}$ A referida Lei, dentre diversos aspectos, proibiu o financiamento eleitoral por pessoas jurídicas.
} 
atos ilícitos entre lobistas e membros da classe política pode também ser praticado por empresas do setor minerário.

A forte importância econômica da mineração fomenta estreitas relações com a esfera política, podendo resultar na aprovação de textos legais, como projetos de Lei, que atendam a interesses mútuos. Nesse sentido, não estão descartados riscos de que projetos de interesse público sobre barragens não sejam adequadamente avaliados e sejam aprovados, ainda que com a subestimação de riscos importantes (SAMPAIO, 2019). Neste contexto, alguns projetos de Lei (PL) foram propostos nos últimos anos no país, com destaque ao PL n 3676/2016, também conhecido como "Mar de Lama Nunca Mais". Esse PL pode ser entendido como uma reação política ao desastre de Fundão, exigindo o endurecimento das normas de licenciamento, a imposição de regras mais rígidas de segurança para barragens, a criação de uma política estadual para proteger atingidos por barragens e a proibição da existência de barragens com alteamento a montante. Entretanto, a partir de 2017 a tramitação do projeto esteve praticamente parada na Assembleia Legislativa de Minas Gerais (ALMG) (SAMPAIO, op. cit.).

No caso do desastre de Brumadinho, contudo, a perda de muitas vidas, o forte envolvimento midiático e a grande comoção nacional, trouxeram pressões à classe política e a necessidade de ação. Assim, foi sancionada, pelo governador, a Lei ${ }^{\circ} 23.291$, de 25 de fevereiro de 2019 (MINAS GERAIS, 2019), derivada da PL 3676/2016 e que propôs uma ampla alteração na legislação minerária no estado de Minas Gerais. Paralelamente, foi aprovada pela ANM a Resolução $n^{\circ}$ 4, de 15 de fevereiro de 2019, que, assim como a lei estadual citada, exigia a proibição da existência de barragens com alteamento a montante (ANM, 2019a). Dessa forma, foi determinado que barragens construídas com o método a montante ou por método declarado como desconhecido poderiam permanecer ativas até a data de 15 de agosto de 2021, concluindo o seu processo de descomissionamento ou descaracterização até a data de 15 de agosto de 2023.

Entretanto, posteriormente a ANM também publicou a Resolução $\mathrm{n}^{\circ} 13$, de 8 de agosto de 2019, que determinou datas para a conclusão da descaracterização dessas barragens conforme o volume de rejeitos contidos pelas estruturas (ANM, 2019b). Assim, para barragens com volume de até 12 milhões de metros cúbicos ficou acordada a data de 15 de setembro de 2022, entre 12 e 30 milhões de metros cúbicos em 15 de setembro de 2025, e superior a 30 milhões de metros cúbicos em 15 de setembro de 2027. O banco de dados da ANM informa que há atualmente 84 barragens de rejeitos construídas ou alteadas pelo método "a montante" ou por método declarado como desconhecido. Logo, essas barragens passarão pelo processo de descaracterização seguindo as determinações da legislação vigente. Dentre elas, estão as barragens 1 e 2 da Mina do Engenho, em 
Rio Acima (MG), que foram abandonadas em $2011^{9}$ e permanecem trazendo riscos ambientais importantes. Em caso de rompimento, os rejeitos podem afetar a captação de água feita pela Companhia de Saneamento de Minas Gerais (COPASA) no manancial de Bela Fama (Rio das Velhas), município de Nova Lima, comprometendo o abastecimento de água de quase metade da população da Região Metropolitana de Belo Horizonte (COTA, et al. 2019).

Outras mudanças na legislação estão em tramitação em decorrência do desastre de Brumadinho, visando tornar a atividade minerária no país mais segura. Em junho de 2019 a Câmara dos Deputados aprovou o PL 2791/19, que altera várias normas da Política Nacional de Segurança de Barragens (Lei 12.334/10) e também do Código de Mineração (Decreto-Lei 227/67) (PIOVESAN, 2019a). Dentre elas está a criação da Zona de Auto Salvamento (ZAS), que se configura como uma área à jusante da barragem na qual não há tempo de intervenção das autoridades em caso de emergência. Assim, no caso de barragens em operação, fica proibida a presença de comunidades nessa zona, cabendo ao empreendedor reassentar as comunidades em outra localidade. Já no caso do planejamento de futuras barragens, a presença de possíveis comunidades dentro da ZAS implica na proibição da construção. Em relação à fiscalização, este PL determina a criação de um sistema de credenciamento de pessoas capacitadas para atestar a segurança das barragens. Logo, o empreendedor deve contratar os serviços de auditoria para atestar a segurança de uma barragem somente entre os credenciados. Em caso de rompimento, o laudo técnico deverá ser realizado por peritos independentes sob a coordenação do órgão fiscalizador e pagos pelo empreendedor (PIOVESAN, op. cit.).

Ainda se tratando de possíveis rompimentos que tragam significativa degradação do meio ambiente ou dos recursos hídricos, bem como danos ao patrimônio de pessoas e comunidades, o empreendedor pode perder a concessão da lavra. A nova legislação ainda prevê o endurecimento das penalidades com multas de até um bilhão de reais. Outros projetos de lei foram criados, dentre eles o PL 2788/19 que foi aprovado na Câmara dos Deputados e institui a Política Nacional de Direitos das Populações Atingidas por Barragens, garantindo uma assistência mais justa aos afetados por rompimentos (PIOVESAN, 2019b). Há também o PL 2787/19 que tipifica rompimentos de barragens como crime de ecocídio. Todos esses projetos de lei foram encaminhados para o Senado e ainda precisam de aprovação. Espera-se que eles fomentem, no setor de mineração do país, maior transparência e segurança em termos socioambientais, reduzindo a possibilidade de novos desastres. Contudo, ainda existem outras questões a serem abordadas no contexto da mineração brasileira.

\footnotetext{
${ }^{9}$ A Mina do Engenho era uma mina de ouro pertencente a Mundo Mineração, do grupo australiano Mundo Mineral. No final de 2011, as atividades cessaram e a estrutura foi abandonada. Ficaram as barragens de rejeitos 1 e 2 que, sem a manutenção adequada, apresentam riscos de rompimento. O Estado ficou com o ônus de administrar as instalações abandonadas e minimizar os riscos, questões que deveriam ter ficado a cargo da empresa (PARREIRAS, 2019).
} 
A atividade minerária, por envolver recursos econômicos expressivos, torna-se um atrativo catalisador da atenção de grandes empreendedores, mas também do poder público e da sociedade dos municípios nos quais possam se instalar. Dessa forma, a classe política tende a se envolver diretamente no setor e participar de processos de guerra fiscal nos quais os municípios e estados batalham por empreendimentos, oferecendo facilidades que visam atrair as empresas (FONSECA, 2019). Nesse sentido, os políticos envolvidos atraem prestígio ao angariar empreendimentos que levam recursos financeiros e empregos diretos e indiretos (com a geração de cadeias de prestação de serviços) para municípios e estados em uma lógica de fomento ao "desenvolvimento".

Entretanto, não é difícil imaginar que um dos principais atrativos para a classe política é a Compensação Financeira pela Exploração de Recursos Mineral (CFEM), também conhecida como os "royalties da mineração". A CFEM se configura como uma contraprestação paga à União, Estados e municípios onde ocorrem a extração pelo aproveitamento econômico de determinado recurso mineral, sendo regulamentada pelo Decreto $\mathrm{n}^{\circ} 1$, de 11 de janeiro de 1991 (BRASIL, 1991). Conforme a Lei $\mathrm{n}^{\mathrm{o}} 13.540$, de 18 de dezembro de 2017, as alíquotas dos minerais extraídos no Brasil variam entre $1 \%$ e 3,5\% (BRASIL, 2017). O minério de ferro, por exemplo, tem uma alíquota de 3,5\%. Logo, a atividade minerária aporta uma significativa quantidade de recursos financeiros, particularmente a municípios dos estados de Minas Gerais e Pará, como ilustra a Tabela 1. Por outro lado, as taxas cobradas no Brasil são marcadamente inferiores às de países como Estados Unidos (5\% a 12,5\%) e Canadá (3\% a 9\%) (SILVA, 2006).

Tabela 1 - Municípios brasileiros com maior arrecadação da CFEM em 2019.

\begin{tabular}{lc}
\hline \multicolumn{1}{c}{ Município - Estado } & Valor em R\$ \\
\hline 1 - PARAUAPEBAS - PA & $1.156 .139 .681,25$ \\
2 - CANAÃ DOS CARAJÁS - PA & $706.068 .474,12$ \\
3 - CONGONHAS - MG & $284.157 .465,30$ \\
4 - ITABIRA - MG & $241.078 .393,45$ \\
5 - NOVA LIMA - MG & $197.805 .274,30$ \\
6 - CONCEIÇÃO DO MATO DENTRO - MG & $180.902 .066,95$ \\
7 - SÃO GONÇALO DO RIO ABAIXO - MG & $160.027 .388,02$ \\
8 - MARABÁ - PA & $134.098 .280,77$ \\
9 - ITABIRITO - MG & $106.906 .775,44$ \\
10 - MARIANA - MG & $83.089 .486,62$ \\
11 - BRUMADINHO - MG & $72.625 .996,35$ \\
12 - BELO VALE - MG & $59.184 .033,16$ \\
13 - ITATIAIUÇU - MG & $57.882 .004,35$ \\
14 - CATAS ALTAS - MG & $53.700 .038,05$ \\
15 - PARACATU - MG & $53.165 .704,04$ \\
\hline
\end{tabular}

Fonte: Dados fornecidos pela $\mathrm{ANM}^{10}$.

10 Disponível em: < https://sistemas.dnpm.gov.br/arrecadacao/extra/Relatorios/cfem/maiores_arrecadadores.aspx>. Acesso em: 15 de janeiro de 2020. 
Um desafio importante é a adequada aplicação dos recursos financeiros no estímulo ao desenvolvimento municipal, à melhoria da qualidade de vida da população, em investimentos na infraestrutura e à diversificação das atividades econômicas municipais, como é o principal objetivo da CFEM (TRIBUNAL DE CONTAS DA UNIÃO, 2018). A concepção da CFEM envolveu a discussão da necessidade de os municípios não dependerem exclusivamente da atividade minerária, o que se configura como uma situação de forte vulnerabilidade econômica. Em caso de interrupção, redução ou término da atividade, os municípios podem ser levados a uma situação de caos econômico e forte elevação das taxas de desemprego. Entretanto, a realidade da maioria dos municípios minerários no Brasil é de forte dependência dos recursos da CFEM, inclusive para fins que não são aqueles para os quais ela foi concebida. Este é o caso do pagamento do funcionalismo público municipal (MESSIAS, 2017), o que se configura em um exemplo de desvio dos propósitos da CFEM.

Só em Minas Gerais, 480 municípios dependem dos royalties da mineração para a manutenção de suas atividades essenciais (CORRÊA, 2019). Mariana é um exemplo ilustrativo dos riscos desta dependência. Após o rompimento da barragem de Fundão houve a paralisação das atividades da Samarco e o município, que em 2014 havia recebido R 90 milhões de reais da CFEM, sofreu importantes impactos econômicos com a queda da arrecadação. Como consequência, Mariana foi palco de protestos e pedidos da prefeitura para que as atividades da Samarco fossem retomadas (MAZZOLA; ESTEVES, 2018).

Algumas experiências internacionais podem fornecer ensinamentos aos esforços de evolução legal na segurança de barragens no Brasil. No Canadá, a The Mining Association of Canada (MAC) é uma autarquia responsável pelo estabelecimento de regras a serem seguidas por empresas mineradoras na gestão de rejeitos. A MAC disponibiliza, desde 1998, um documento intitulado The Tailings Guide para orientar o desenvolvimento e a implementação de sistemas de gerenciamento de rejeitos; e um manual denominado OMS Guide (Developing and Operation, Maintenance, and Surveillance Manual for Tailings and Water Management Facilities), visando auxiliar os processos de operação e manutenção de uma barragem, desde a etapa de projeto até o período de monitoramento pós-fechamento (MAC, 2019).

Conforme dito anteriormente, o rompimento de Mount Polley foi causado por uma falha de design decorrente de erros no próprio projeto da barragem. Assim, visando tornar a legislação minerária mais efetiva, a MAC solicitou a elaboração de um relatório que enumerasse recomendações à gestão de barragens de rejeitoss, dentre elas as Best Available Technologies (BAT) e as Best Applicable Practices (BAP). Desta forma, o Ministério de Minas e Energia da Columbia Britânica pretende que as indústrias minerárias busquem e apliquem as melhores práticas 
e tecnologias relacionadas aos tipos de mineração a que se propõem, a fim de se evitar novos rompimentos.

Entretanto, a província da Colúmbia Britânica é marcada por polêmicas envolvendo a mineração, tendo sido chamada "The 'Wild West' of Canadian Political Cash" (LEVIN, 2017). A província é acusada de ser palco de fortes lobbies em prol do setor minerário, os quais são alimentados por doações de empresas para a classe política. Uma líder do governo que ocupou o cargo entre 2011-2017 recebeu mais de 277 mil dólares canadenses do seu partido, oriundos de doações (LEVIN, op. cit.).

Exemplos como estes suscitam desconfianças sobre um certo alinhamento de interesses entre classes políticas e setor minerário em diversos países, com acordos econômicos facilitados que beneficiam governos com a injeção de recursos financeiros e, sobretudo, as empresas minerárias com regalias como subsídios fiscais (MINING, 2019). Segundo Grant (2019), a província da Colúmbia Britânica apresenta leis antiquadas que privilegiam os interesses das mineradoras, gerando uma rápida exploração de recursos que gera importantes impactos ambientais e prejudica as futuras gerações. Tais impactos têm gerado polêmicas com políticos norte-americanos, visto que rios compartilhados entre os Estados Unidos e o Canadá estão sendo poluídos por atividades mineradoras na Columbia Britânica. Como consequência, senadores norte-americanos têm pressionado o governo da Província, uma vez que esse fato fere o Boundary Waters Treaty de 1909 (GRANT, op. cit.).

No caso da Espanha, a regulamentação das barragens de rejeitos é estabelecida pela Lei $n^{\circ}$ 22/1973, conhecida como Lei de Minas. Após o rompimento da barragem de Los Frailes, em 1998, essa lei sofreu algumas modificações. Nove anos depois do desastre o Artigo $121^{\circ}$ foi alterado, passando a estabelecer as infrações e as respectivas penalidades (ESPANHA, 1973). Este maior detalhamento é relevante quando se considera exemplos como o da empresa Boliden, a qual se recusou a pagar a multa pelo desastre de Aznalcóllar, sempre recorrendo judicialmente e culpando a Geocisa, empresa que construiu a barragem. Em 2002 o governo espanhol havia aplicado uma multa de 43,7 milhões de euros e no mesmo ano a Junta da Andaluzia também exigiu, a título de reparação, uma quantia de 89,9 milhões de euros pelos gastos para restaurar a área afetada (AUNIÓN et. al., 2018). Entretanto, a situação se tornou um imbróglio jurídico entre o governo espanhol e a Junta da Andaluzia contra a Boliden, que se arrasta até os dias atuais. Conforme Aunión et al. (2018), o sistema é falho e, de posse de recursos financeiros para recorrer, conseguese eternizar o caso. Essa situação exemplifica novamente que o poder das mineradoras na condução de situações que favoreçam os seus interesses, tanto no meio político quanto no jurídico, faz parte do contexto internacional. 
A referida alteração na Lei de Minas acabou permitindo que o Estado espanhol passasse a ter maior respaldo legal para lidar com infrações no âmbito do setor minerário. Em 2009, as condições de titularidade de direitos de mineração, presentes nos artigos $83^{\circ}$ a $90^{\circ}$, foram retiradas da Lei. Ainda em 2009, foi promulgado um decreto sobre gestão de resíduos das indústrias extrativas e de proteção e reabilitação do espaço afetado por atividades mineradoras (ESPANHA, 2009). Esse decreto teve como função orientar as empresas para que a gestão dos rejeitos seja a mais eficaz possível, minimizando os seus efeitos ambientais. Em 2010, foi adicionado o inciso IV no artigo $1^{\circ}$, estabelecendo que a exploração de estruturas subterrâneas possua legislação própria, para além da Lei de Minas. Já em 2014, adicionou-se ao artigo $76^{\circ}$ o sistema de referência geográfica a ser usado na elaboração das Permissões de Concessão de Exploração em cada região da Espanha. Todas essas medidas foram tomadas de modo a modernizar a legislação espanhola voltada para a mineração.

\section{CONSIDERAÇÕES FINAIS}

A mineração tem um papel chave no desenvolvimento tecnológico da humanidade ao longo da história, fornecendo diversos recursos para diferentes finalidades. Logo, o setor minerário é um dos pilares da economia global. A partir do século XX, houve uma ampla expansão da mineração no mundo, especialmente após a Segunda Guerra Mundial. Esse fato contribuiu também para um aumento considerável dos eventos envolvendo rompimentos de barragens de rejeitos. Os números pouco precisos de barragens no mundo trazem dificuldades para se determinar com exatidão o número de desastres associados a rompimentos. Conforme os dados levantados, entre os anos de 1910 e 2019 foram identificados 250 eventos. Estes ocorreram principalmente na América do Norte, muitos com causas desconhecidas e se concentrando entre as décadas de 1960 e 1980.

A implementação de técnicas de construção mais modernas assim como a adoção de medidas de segurança mais eficientes contribuiu para que a ocorrência de desastres tenha diminuído nas últimas décadas, em nível global. Assim, fica evidente que a mineração ao longo dos séculos XX e XXI sofreu uma profunda evolução em termos globais, se tornando uma atividade econômica mais segura. Por outro lado, estes avanços não impedem que rompimentos de barragens ainda ocorram, conforme mostrado pelos incidentes de Aznalcóllar, Mount Polley, Fundão e Brumadinho. A mencionada evolução tecnológica não é efetivada de modo padronizado ao longo dos países e não foi capaz de evitar dois dos maiores desastres socioambientais no Brasil. Esses eventos apresentam em comum problemas de administração/gestão que envolvem lacunas no aparato jurídico-institucional e a real efetivação e fiscalização das exigências legais, abarcando tanto o setor minerário quanto o poder público dos países envolvidos. Interesses políticos e econômicos de 
empresas e governos podem se mesclar em quaisquer países, contribuindo para o quadro dos riscos ambientais associados às barragens de rejeitos.

O Brasil ainda apresenta uma legislação pouco eficaz e permissiva aos interesses das grandes mineradoras, bem como atitudes duvidosas de membros da classe política alinhados ao setor minerário. Entretanto, os recentes desastres nacionais têm forçado uma mudança desse cenário. Espanha e Canadá, por sua vez, apresentam um panorama de gestão que se apresenta mais rigoroso, o que não exclui a existência de problemas. O trabalho aponta que, mesmo nesses países, as mineradoras atuam pressionando o meio político em prol dos seus interesses.

\section{AGRADECIMENTOS}

Os autores agradecem à CAPES pela bolsa de doutorado; ao CNPq pela bolsa de pesquisa e apoio financeiro (Projeto 407704/2019-3); à FAPEMIG (Projeto CRA-APQ-00231-17) e ao Grupo de Pesquisa RIVUS (Geomorfologia e Recursos Hídricos - CNPq/UFMG).

\section{REFERÊNCIAS}

ADEN, A. The Impact of the Mount Polley Tailings Pond Failure on the Sedimentary Record of Quesnel Lake, British Columbia. 2018. 101 f. Dissertação (Mestrado em Ciências) Department of Geography and Planning, University of Toronto, Toronto, 2018.

ALONSO, E. E.; GENS, A. Aznalcóllar dam failure. Part 1: Field observations and material properties. Géotechnique, v. 56, n. 3, p. 165-183, 2006.

ANM - AGÊNCIA NACIONAL DE MINERAÇÃO. Resolução no 4, de 15 de fevereiro de 2019a. Estabelece medidas regulatórias objetivando assegurar a estabilidade de barragens de mineração, notadamente aquelas construídas ou alteadas pelo método denominado "a montante" ou por método declarado como desconhecido e dá outras providências. Disponível em: $<$ http://www.anm.gov.br/assuntos/barragens/resolucao-no-4-de-15-de-fevereiro-de-2019>. Acesso em: 15 jan. 2020.

ANM - AGÊNCIA NACIONAL DE MINERAÇÃO. Resolução no ${ }^{\mathbf{1 3}}$, de 8 de agosto de $2019 b$. Estabelece medidas regulatórias objetivando assegurar a estabilidade de barragens de mineração, notadamente aquelas construídas ou alteadas pelo método denominado "a montante" ou por método declarado como desconhecido e dá outras providências. Disponível em: $<$ http://www.anm.gov.br/assuntos/barragens/resolucao-anm-no-13-de-8-de-ago.pdf/view $>$. Acesso em: 15 jan. 2020.

ARAfAT, M. A. A. Back Analysis of Mount Polley Tailing Dam Failure. 2017. $100 \mathrm{f}$. Dissertação (Mestrado em Ciências) - York University, Toronto, 2017.

AUNIÓN, J.; MORA, A.; PLANELLES, M. Cuando el que contamina no paga. Eı País, 22 de abril de 2018. Disponível em: <https://elpais.com/politica/2018/04/20/actualidad/15248_103979.html>. Acesso em: 6 set. 2019. 
AZAM, S.; LI, Q. Tailings Dam Failures: A Review of the Last One Hundred Years. Waste Geotechnical News, v. 28, n. 4, p. 50-53, 2010.

BRASIL. Decreto $n^{\circ} 1$, de 11 de janeiro de 1991. Regulamenta o pagamento da compensação financeira instituída pela Lei $\mathrm{n}^{\mathrm{o}} 7.990$, de 28 de dezembro de 1989, e dá outras providências. Disponível em: <http://www.planalto.gov.br/ccivil_03/decreto/1990-1994/D0001.htm>. Acesso em: 15 jan. 2020.

BRASIL. Lei $\mathbf{n}^{\circ}$ 12.334, de 20 de setembro de 2010. Estabelece a Política Nacional de Segurança de Barragens destinadas à acumulação de água para quaisquer usos, à disposição final ou temporária de rejeitos e à acumulação de resíduos industriais, cria o Sistema Nacional de Informações sobre Segurança de Barragens e altera a redação do art. 35 da Lei no 9.433, de 8 de janeiro de 1997, e do art. 4o da Lei no 9.984, de 17 de julho de 2000. Disponível em: <http://www.planalto.gov.br/ccivil_03/_Ato2007-2010/2010/Lei/L12334.htm>. Acesso em: 15 jan. 2020.

BRASIL. Lei $\mathbf{n}^{\mathbf{0}} \mathbf{1 3 . 5 4 0}$, de 18 de dezembro de 2017. Altera as Leis $\mathrm{n}^{\circ} 7.990$, de 28 de dezembro de 1989, e 8.001, de 13 de março de 1990, para dispor sobre a Compensação Financeira pela Exploração de Recursos Minerais (CFEM). Disponível em: $<$ http://www.planalto.gov.br/ccivil_03/_Ato2015-2018/2017/Lei/L13540.htm>. Acesso em: 15 jan. 2020 .

BROWN, R.; ROSTE, G.; BARON, J.; REES, C. Technical Report on the Mount Polley Mine Report for: Imperial Metals Corporation. Vancouver, 2016. 203 p.

CAMPOS, J. I. Lobby e parlamento: Estudo de caso da atuação da assessoria de relações governamentais da FIESP no Congresso Nacional brasileiro. 2017. 57 f. Monografia (Trabalho de Conclusão de Curso) - Especialização em Poder Legislativo Centro de Formação, Treinamento e Aperfeiçoamento da Câmara dos Deputados/Cefor, Brasília, 2017.

CORRÊA, F. Em Minas Gerais, 480 cidades dependem dos royalties da mineração. O Tempo, 4 de fevereiro de 2019. Disponível em: <https://www.otempo.com.br/cidades/em-minas-gerais-480cidades-dependem-dos-royalties-da-mineracao-1.2131108>. Acesso em: 18 jul. 2019.

COTA, G. E. M.; ROSA, N. M. G.; ROMEIRO, C. E.; MENDES, I. A. S.; MAGALHÃES JÚNIOR, A. P. Aspectos legais da segurança de barragens de rejeitos de minério: implicações para a qualidade ambiental e usos múltiplos da água no alto Rio das Velhas (MG). Geographia, v. 21, n. 45, p. 32-46, 2019.

D’AGOSTINO, L. F. Praias de barragens de rejeitos de mineração: características e análise da sedimentação. 2008. 244 f. Tese (Doutorado em Engenharia Mineral) - Escola Politécnica, Universidade de São Paulo, São Paulo, 2008.

ESPANHA. Jefatura del Estado. Ley n ${ }^{\circ} 22$, de 21 de julio de 1973. Ley de Minas. 8. ed. Madrid. 1973. $18 \mathrm{p}$.

ESPANHA. Ministerio de la Presidencia. Ley n ${ }^{\circ}$ 975, de 12 de junio de 2009. Real Decreto sobre gestión de los residuos de las industrias extractivas y de protección y rehabilitación del espacio afectado por actividades mineras. Madrid, 2009.

EXAME. Bombeiros encontram corpo intacto de vítima de Brumadinho. 4 de julho de 2019. Disponível em: <https://exame.abril.com.br/brasil/bombeiros-encontram-corpo-intacto-de-vitimade-brumadinho/>. Acesso em: 22 jul. 2019. 
FONSECA, M. Minas Deixa de Arrecadar 6 bi; Dinheiro Salvaria Saúde. Estado de Minas, 20 de maio de 2019. Disponível em: $<$ https://www.em.com.br/app/noticia/politica/minas-deixa-dearrecadar-r-6-bi-dinheiro-salvaria-saude.shtml>. Acesso em: 12 out. 2019.

GENS, A.; ALONSO, E. E. Aznalcóllar dam failure. Part 2: Stability conditions and failure mechanism. Géotechnique, v. 56, n. 3, p. 185-201, 2006.

GRANT, C. US senators press Horgan to clean up BC mine water. Kimberley Bulletin, 18 de junho de 2019. Disponível em: $<$ https://www.kimberleybulletin.com/news/us-senators-press-horganto-clean-up-bc-mine-water/>. Acesso em: 6 set. 2019.

GUDYNAS, E. Hay alternativas al extractivismo: transiciones para salir del viejo desarrollo. 1. ed. Lima: Centro Peruano de Estudios Sociales, 2012. 44p.

IBRAM - Instituto Brasileiro de Mineração. Relatório Anual de Atividades - julho de 2017 a junho de 2018. [s.1.], 2018. 38p.

ICOLD - International Commission on Large Dams. Dams Safety. Disponível em: $<$ https://www.icold-cigb.org/GB/dams/dams_safety.asp>. Acesso em: 10 jul. 2019a.

ICOLD - International Commission on Large Dams. World Register of Dams - General Synthesis. Disponível em: <https://www.icold-cigb.org/GB/world_register/general_synthesis.asp $>$. Acesso em: 10 jul. $2019 b$.

JUSBRASIL. Praticar "lobby" é crime? 2015. Disponível em: <https://portaljustificando.jusbrasil.com.br/noticias/246133417/praticar-lobby-e-crime>. Acesso em: 18 ago. 2019.

LEVIN, D. British Columbia: The 'Wild West' of Canadian Political Cash. The New York Times, 13 de janeiro de 2017. Disponível em:<https://www.nytimes.com/2017/01/13/world/canada/britishcolumbia-christy-clark.html>. Acesso em: 6 set. 2019.

MAC - THE MINING ASSOCIATION OF CANADA. Developing an Operation, Maintenance, and Surveillance Manual for Tailings and Water Management Facilities. $2^{\mathrm{a}}$ ed., 2019. $70 \mathrm{p}$. Disponível em: <https://mining.ca/wp-content/uploads/2019/03/MAC-OMS-Guide_2019.pdf $>$. Acesso em: 15 jan. 2020.

MAgalhães JÚNiOR, A. P. A Nova Cultura de Gestão da Água no Século XXI - Lições da experiência espanhola. 1. ed. São Paulo: Editora Edgard Blucher, 2017. 346p.

MARSHALL, J. Rompimentos de barragens de rejeitos no Brasil e no Canadá: uma análise do comportamento corporativo. Caderno Eletrônico de Ciências Sociais, v. 5, n.1, p. 27-46, 2017.

MAZZOLA, B. G.; ESTEVES, K. Gestão de Stakeholders: Fundação Renova e o Desastre de Mariana. In: ENCONTRO INTERNACIONAL SOBRE GESTÃO AMBIENTAL E MEIO AMBIENTE, 20., São Paulo. Anais... São Paulo: 2018. p. 1-17.

MEHARG, A. A.; OSBORN, D.; PAIN, D. J.; SÁNCHEZ, A.; NAVESO, M. A. Contamination of DonÄana food-chains after the Aznalcóllar mine disaster. Environmental Pollution, v. 105, n.3, p. 387-390, 1999. 
MENDES, C. M.; OLIVEIRA, V. V. Rompimento das barragens em Mariana (2015) e em Brumadinho (2019): regimes de interação no contexto das organizações. In: ENCONTRO ANUAL DA ASSOCIAÇÃO NACIONAL DOS PROGRAMAS DE PÓS-GRADUAÇÃO EM COMUNICAÇÃO. 28., Porto Alegre. Anais... Porto Alegre: COMPÓS, 2019. p. 1-23.

MESSIAS, L. S. Choques de receitas e o comportamento dos políticos: evidências a partir dos municípios mineradores no Brasil. 2017. 62 f. Dissertação (Mestrado em Administração Pública e Governo) - Escola de Administração de Empresas de São Paulo, Fundação Getúlio Vargas, São Paulo, 2017.

MILANEZ, B.; LOSEKANN, C. (Org.). Desastre no Vale do Rio Doce: Antecedentes, impactos e ações sobre a destruição. 1. ed. Rio de Janeiro: Folio Digital - Letra e Imagem, 2016. 437p.

MINAS GERAIS. Lei ${ }^{\circ}$ 23.291, de 25 de fevereiro de 2019. Institui a política estadual de segurança de barragens. Disponível em: $<$ https://www.almg.gov.br/consulte/legislacao/completa/completa.html?ano=2019\&num=23291\&ti po $=$ LEI $>$. Acesso em: 15 jan. 2020.

MINING. BC exploration tax credits made permanent. 28 de janeiro de 2019. Disponível em: $<$ https://www.mining.com/bc-exploration-tax-credits-made-permanent/>. Acesso em: 12 out. 2019.

NID - National Inventory of Dams. Interactive Map \& Charts. Disponível em: $<$ https://nid.sec.usace.army.mil/ords/f?p=105:113:14615347930327::NO $>$. Acesso em: 10 jul. 2019.

PARREIRAS, M. Contribuinte terá que pagar R\$ 15 milhões para descaracterização de barragens em Rio Acima. Estado de Minas, 13 de maio de 2019. Disponível em: $<$ https://www.em.com.br/app/noticia/gerais/2019/05/13/interna_gerais,1053463/contribuinte-teraque-pagar-r-15-milhoes-para-descaracterizacao-de-ba.shtml>. Acesso em: 29 jul. 2019.

PIOVESAN, E. Câmara aprova proposta para ampliar segurança em barragens de rejeitos. Câmara dos Deputados, 26 de junho de 2019a. Disponível em: $<$ https://www2.camara.leg.br/camaranoticias/noticias.html>. Acesso em: 17 jul. 2019.

PIOVESAN, E. Câmara aprova política nacional em prol de atingidos por barragens. Câmara dos Deputados, 25 de junho de 2019b. Disponível em: $<$ https://www2.camara.leg.br/camaranoticias/noticias/MEIO-AMBIENTE/578922-CAMARAAPROVA-POLITICA-NACIONAL-EM-PROL-DE-ATINGIDOS-POR-BARRAGENS.html>. Acesso em: 17 jul. 2019.

SAMPAIO, C. Como o lobby de mineradoras trava projetos de interesse público sobre barragens. Brasil de Fato, 28 de janeiro de 2019. Disponível em: $<$ https://www.brasildefato.com.br/2019/01/28/como-o-lobby-de-mineradoras-trava-projetos-deinteresse-publico-sobre-barragens/>. Acesso em: 15 jul. 2019.

SILVA, M. A. R. Royalties da mineração. Cadernos do Naea, Belém, v. 2, n. 3, p. 29-53, 2006.

SOUZA, F.; FELLET, J. Brumadinho é maior acidente de trabalho já registrado no Brasil. BBC, 29 de janeiro de 2019. Disponível em: <https://www.bbc.com/portuguese/brasil-47012091>. Acesso em: 22 jul. 2019. 
TAKAR, T. Barragem brasileira é pior? Problema é fiscalização, punição e lucro alto. UOL, São Paulo, 31 de janeiro de 2019. Disponível em: $<$ https://economia.uol.com.br/noticias/redacao/2019/01/31/como-e-a-seguranca-das-barragens-demineracao-em-outros-paises.htm>. Acesso em: 12 out. 2019.

THE CANADIAN PRESS. Future of Quesnel Lake still unclear after Mount Polley mine disaster: report. CTV NEWS, 5 de maio de 2015. Disponível em: <https://www.ctvnews.ca/politics/futureof-quesnel-lake-still-unclear-after-mount-polley-mine-disaster-report-1.2360009>. Acesso em: 1 ago. 2019.

TRIBUNAL DE CONTAS DA UNIÃO. Relatório de Levantamento - Criação da Agência Nacional de Mineração (ANM). 2018. 48 p. Disponível em: $<$ https://portal.tcu.gov.br/data/files/0D/E3/B3/54/C2B29610DCEE6196F18818A8/017.199-2018-2AC\%20-\%20levantamento\%20CFEM_ANM.pdf>. Acesso em: 12 out. 2019.

UNEP - United Nations Environment Programme. New report urges global action on mining pollution, 13 de novembro de 2017. Disponível em: <https://www.unenvironment.org/news-andstories/story/new-report-urges-global-action-mining-pollution>. Acesso em: 22 jul. 2019.

WILLIAMS, K. Mount Polley mine tailings spill: Imperial Metals could face \$1M fine. CBC, 6 de agosto de 2014. Disponível em: <https://www.cbc.ca/news/canada/british-columbia/mount-polleymine-tailings-spill-imperial-metals-could-face-1m-fine-1.2728832>. Acesso em: 1 ago. 2019.

WISE Uranium Project. Chronology of major tailings dam failures. Disponível em: $<$ https://www.wise-uranium.org/mdaf.html $>$. Acesso em: 22 jul. 2019.

ZHANG, L. M.; XU, Y.; JIA, J. S. Analysis of earth dam failures - A database approach. In: INTERNATIONAL SYMPOSIUM ON GEOTECHNICAL SAFETY \& RISK. 1., 2007, Shangai. Proceedings... Shangai, 2007. P. 293-302. 